\title{
LA 'MANIFESTACIÓN EVIDENTE DEL DAÑO AMBIENTAL' COMO REQUISITO DE LA ACCIÓN CIVIL INDEMNIZATORIA POR DAÑO AMBIENTAL
}

\section{THE EVIDENT MANIFESTATION OF ENVIRONMENTAL DAMAGE AS A REQUIREMENT FOR THE CIVIL COMPENSATORY ACTION BY ENVIRONMENTAL DAMAGE}

Santiago Zárate González*

\section{RESUMEN}

El presente trabajo analizamos uno de los presupuestos de la acción indemnizatoria por daño ambiental contemplada en el art. 63 de la Ley n. ${ }^{\circ}$ 19300: la manifestación evidente del daño ambiental; aspecto que presenta dificultades en el ámbito de interpretación de categorías extrajurídicas como las representadas en la frase "manifestación evidente" utilizada en el texto legal. Esto provoca la necesidad de saber en qué medida esa representación fáctica denominada "manifestación del daño ambiental" puede constituir una limitante al momento de decidir un litigio en que se discuta la existencia del mismo. Las modificaciones legales posteriores (Ley n. ${ }^{0}$ 20600, que crea los tribunales ambientales) no empecen el entendimiento de los conceptos que planteamos en el presente trabajo. Es más, sostenemos que el requisito de manifestación evidente no lo es respecto de la acción por daño ambiental que se regula en la Ley n. ${ }^{\circ}$ 20600, sino que a la acción civil indemnizatoria del daño que sigue encontrándose incólume en la Ley $\mathrm{n}^{\circ}$ 19300. De hecho, las modificaciones introducidas al procedimiento en la primera ley citada, no perjudican el presente análisis.

Palabras ClaVe: Manifestación, daño ambiental, acción indemnizatoria.

* Docente Universidad Central de Chile. Doctor en derecho por la Pontificia Universidad Católica de Valparaíso y abogado de la Pontificia Universidad Católica de Chile. Dirección postal: Cochrane 417 A, Santiago. Correo electrónico: santiago.zarate@ ucentral.cl. Artículo recibido el 16 de abril de 2019 y aceptado para su publicación el 4 de junio de 2019 . 


\begin{abstract}
The purpose of this paper is to analyze one of the budgets of the compensation action for environmental damage contemplated in Article 63 of Law 19,300: evident manifestation of environmental damage; aspect that presents difficulties at the level of interpretation of extralegal categories such as those represented in the phrase "evident manifestation" used in the legal text. This causes the need to analyze to what extent that factual representation called 'manifestation of environmental damage' can constitute a limitation when deciding a litigation in which the existence of the same is discussed. Subsequent legal modifications (law 20,600, for example, created by environmental tribunals) do not start the understanding of the concepts we propose in this work. Moreover, we argue that the evident manifestation requirement is not with respect to the action for environmental damage that is regulated by Law 20,600, but rather to the civil action for compensation of the damage that is still unharmed by Law 19,300. In fact, the modifications introduced to the procedure in the first law cited do not prevent the present analysis.
\end{abstract}

KEY WORDS: Manifestation, Environmental damage, Compensatory action.

\title{
I. INTRODUCCIÓN
}

La Ley n. ${ }^{\circ} 19300$ sobre Bases del Medio Ambiente, consagra, según se asevera por la doctrina nacional ${ }^{1}$, el principio de responsabilidad ambiental, estatuto que emanaría, a su turno, de su art. 51 inciso $1^{\circ}$, el cual señala: "Todo el que culposa o dolosamente cause daño ambiental, responderá del mismo en conformidad a la presente ley", determinando a priori, que solo de acuerdo con esta ley es que una persona puede llegar a ser sujeto pasivo de la acción indemnizatoria por daño ambiental. Es decir, es la propia ley en este artículo la que señala una regla particular y específica de responsabilidad que encuentra su fuente en la Ley n 19300 y su reglamento. Aparte de estas normas, no parece plausible estar ante un estatuto extendido de responsabilidad civil. Sin embargo, vamos a suponer que la responsabilidad ambiental existe y que se rige por el estatuto de la Ley de Bases, el reglamento y, en forma supletoria, aquellas normas del Código Civil sobre responsabilidad extracontractual (inciso final del art. 51).

${ }^{1}$ Bermúdez (2007), p. 224. También en Corral (2004), p. 264; Vidal (2008), pp. 191 210; VIDAL (2007), pp. 119-140. 
Comenzaremos por saber qué se ha entendido por "manifestación evidente del daño", según se señala en el art. 63 de la Ley de Bases, y de cómo este elemento objetivo (material) ha podido influir en la decisión de admisión o no de una acción destinada a reparar el mal ambiental causado, haciéndonos dos preguntas, las cuales una vez contestadas, darán paso al análisis de algunas sentencias que, a nuestro entender, marcan una tendencia en esta materia. Las interrogantes son:

1. ¿qué se entiende por daño ambiental?; y, en esa medida,

2. ¿a qué se refiere la ley cuando habla de manifestación evidente del daño ambiental?

En ambos casos, abordaremos las respuestas a tales interrogantes desde la perspectiva dogmática y procedimental, que permitan una mejor percepción del problema que planteamos.

1. ¿Qué se entiende por daño ambiental? La respuesta a esta pregunta se encuentra en la misma ley. $\mathrm{El}$ art. $2^{\circ}$, letra e), define lo que debe entenderse por daño ambiental, al siguiente tenor: "Toda pérdida, disminución, detrimento o menoscabo significativo inferido al medio ambiente o a uno o más de sus componentes". Se puede advertir que los conceptos de 'pérdida', 'disminución', 'detrimento' y 'menoscabo', son términos equívocos, pues a la unidad de los mismos corresponden varios significados, pero acotados a la materia de que se trata. Es decir, cualquiera que sea el significado que se otorgue a las palabras mencionadas, este debe adecuarse al contexto en el que ellas se expresan. Resulta, entonces, que esos términos de la definición legal no suscitan mayor complejidad, lo que no podemos aseverar de los términos 'inferir', y 'componente', utilizados también en la norma en cuestión.

En una primera acepción 'inferir' significa aquello que se colige o se deduce $^{2}$. En una segunda acepción, el término se vuelve menos asertivo, ya que significa causar un mal, un grave daño u ofensa. Resulta ser más adecuado, en consecuencia, entender el término 'inferir' como causar un daño grave. Por su parte, la palabra 'componente', nos remonta a otro estadio, puesto que la palabra posee un significado más unívoco que inferir, pues significa cualquier elemento que forme parte de una cosa. En el caso del ambiente, podemos colegir que el término alude a aquellos elementos del entorno que

${ }^{2}$ De Mora (2007), p. 243, respecto del término inferir: "Se infiere y se deduce de las pruebas y de los hechos; se colige de los indicios y de las analogías. El que infiere y el que deduce sacan consecuencias; el que colige aventura un juicio. El lógico y el matemático deducen o infieren consecuencias y corolarios; los inteligentes en minería coligen por el color de la tierra la presencia de los metales. Sin embargo, no es perfecta la sinonimia entre inferir y deducir. Deducir supone un trabajo más complicado y mayor número de antecedentes que inferir. Se infiere de un hecho, de una proposición, de un principio; se deduce de muchos hechos, de muchas proposiciones, de muchos principios. Descartes ha dicho: Pienso, luego existo. Esto es inferir, no deducir”. 
rodea al ser humano. Por ello, entonces, en virtud de la definición planteada en la ley, podemos consensuar en que se producirá un daño ambiental cada vez que se exista una pérdida, disminución, detrimento o menoscabo que altere el entorno de una persona o del lugar donde habita.

Un dato curioso de la definición lo proporciona el significado que el conjunto de palabras que se encuentran antes de la palabra 'inferir', en tanto significantes del término 'daño' (pérdida, disminución, detrimento o menoscabo), de modo que se asume que el legislador quiso asegurarse de que el operador jurídico no pudiere darle otro significado que aquel directamente relacionado con los conceptos de la responsabilidad civil extracontractual.

Desde la perspectiva planteada, no reviste mayor interés saber si la construcción del tipo legal se adecuó o no a una técnica depurada, o si el legislador ha querido dejar claro que todo deterioro por muy pequeño que sea implica un daño especial referido al ambiente. Nos inclinamos por la segunda opción, al menos a estas alturas, porque no se advierte mayor complejidad en los conceptos. Pensamos que lo mismo sucede con el término 'significativo', que se ubica al final de los significantes de la palabra 'daño', como ya hemos dicho.

Por consiguiente, nos parece que el legislador quiso dejar prístino el concepto de "daño ambiental", tanto con la serie de términos significantes 104 del daño, como respecto de la palabra 'significativo', en que se advierte que la misma ha sido utilizada para efectos de realzar la importancia que debe tener el daño para que la ley conceda una acción indemnizatoria.

2. ¿A qué se refiere la ley con "manifestación evidente del daño ambiental"? Esta es la pregunta más relevante, ya que, definido que ha sido el daño ambiental, nos resta preocuparnos de esta expresión usada en la ley.

Se sabe que las ciencias naturales se guían por verdades apodícticas, de modo que cualquier modificación importante de sus postulados, las tornan paradigmáticas. Es decir, cada vez que se formula un enunciado necesario y verdadero desde el punto de vista lógico-formal, suele confiarse en que jamás cambiará. Cuando lo hace, no obstante, se habla de un paradigma. Las ciencias naturales, en esa medida, son explicadas a partir de su verificación empírica, lo cual permite afirmar y afianzar el postulado lógico de sus premisas. El principio que impera en esta clase de ciencia es el de causalidad o determinismo, por lo que sus elementos objetivos serán siempre establecidos a partir de la realidad observada.

Por ello, aunque la noción de daño resulta ser un entimema en cuanto concepto, sin embargo, es, a la vez, una noción cuyo significado no es unívoco. Ludwig Wittgenstein señalaba: "el significado de una palabra es su uso en el lenguaje"3, de modo que cualquiera otro que pretenda dársele

${ }^{3}$ Wittgenstein (2004), vol. 43, p. 61. 
hará que el sujeto receptor del mensaje lingüístico transmitido por ella, no la logre comprender y aprehender, posibilitando, entonces, que ese sujeto no entienda aquello de lo que se habla.

Con todo, debemos reconocer en esta primera mirada a la Ley de Bases del Medio Ambiente que al menos en sus definiciones, es bastante asertiva e innovadora para su época.

Por otra parte, ¿de qué manera podemos saber que estamos frente a un daño si no es en función de algo (objeto) o, de alguien (sujeto)? Esto, porque, por lo general, se suele dañar una cosa, o a otro. En otras palabras, se requiere de una relación de alteridad tanto real como personal al momento de producirse un evento dañoso, pues si no existe esa relación, no podremos hablar de un daño efectivo y real. Así, si nos pasamos un disco pare y nadie nos observa y no hay una colisión, se dice que no hubo un evento dañoso, a pesar de haber existido una infracción de la ley. Pero, si pasamos y se produce una colisión, ese evento se convierte en dañoso. La infracción normativa hace procedente el resarcimiento de ese daño, fundado en el brocardo de que todo daño debe ser indemnizado. Todo lo anterior, porque el sistema para que opere presupone que el daño exista.

Otra cosa es cómo este se verifique o manifieste en la realidad, en el entorno, siguiendo los postulados de Martin Heidegger. En efecto, pues, ¿qué es el mundo que nos rodea sino nuestro entorno o hábitat? Es nuestro ser-estar-ahí (dasein) ${ }^{4}$.

\section{DE LA EXPRESIÓN “MANIFESTACIÓN DEL DAÑO”}

La expresión "manifestación del daño" refiere a un aspecto objetivo que resulta ser un requisito sine qua non para la interposición de la acción por daño ambiental. Planteamos que se trata de un requisito del tipo anotado, ya que si el daño no se manifiesta (si el detrimento o menoscabo del ambiente o entorno no se concretiza en la realidad), y además, esta no es observada o se hace ostensible, como debida o por efecto de algo o de alguien; la acción, pues, no podrá ser impetrada.

Debemos recordar que "medio ambiente" es un concepto, y como tal, es una idea, una noción que designa cosas, pero por convención. Cuando a Isaac Newton le cae la manzana en la cabeza, lo que en realidad le cae es un apple, palabra que designa, en Inglaterra, a aquella fruta que conocemos como manzana. De este modo, en consecuencia, cuando hablamos de "manifestación", no es del concepto, sino que de la circunstancia de que algo se da en la realidad de manera explícita o patente.

\footnotetext{
${ }^{4}$ Heidegger (1997), pp. 108-118. También en MuÑoz (2015), pp. 95-110.
} 
Sin embargo, esta "manifestación del daño ambiental" contiene algunas sutilezas que es conveniente comentar. Cuando hablamos del daño con antelación, aseveramos que este es un concepto que alude no a un evento o hecho en sí, sino que a una noción construida a partir de algo que ha ocurrido en la realidad -valga toda redundancia -, y que, al traspasar la línea de la legalidad (mera legalidad como la llamaba Immanuel Kant), no imprimió en la Ley de Bases alguna significación que haga aplicable una sanción posterior, como podríamos pensar.

No todo evento da lugar a un daño. Debe, por tanto, cumplirse con una doble exigencia:

i) que el Derecho establezca la conducta en un tipo que la describa (tipo legal, no necesariamente de naturaleza penal) y,

ii) que el evento se produzca "debido a...”, o, "a consecuencia de..."; expresiones que aluden a la causalidad, que es el principio rector en esta materia.

Así, entonces, cuando se produce un hecho que provoca, ya sea en un sujeto o en un objeto, al menos, una alteración significativa en su estado o composición corpórea, y esa conducta se encuentre tipificada legalmente (descrita en la ley); estaremos en presencia de un daño. Los demás hechos de la realidad, no interesan al derecho.

$106 \quad$ Ahora bien, que algo se manifieste significa que se exprese de alguna manera en la realidad "de alguna forma", por cuanto los hechos se manifiestan de distintas maneras. De ahí que la manifestación de algo pueda ser hasta imperceptible.

"Manifestar" es, en este sentido, y con respecto a lo analizado, revelar, mostrar algo ${ }^{5}$. Por su lado, 'evidente' es aquello claro, obvio, que se percibe fácilmente. La preposición ex que acompaña al calificativo videns -participio activo de ver- da como resultado que la palabra 'evidente' coloca al hecho desde fuera, cuestión que se ve, que se aprecia, "desde fuera de [...]"6. En consecuencia, "evidente" es aquello que se aprecia con claridad desde que existe algún signo que manifieste su existencia.

Por ello, cuando en el art. 63 de la Ley de Bases del Medio Ambiente se dice "manifestación evidente", se crea una muy conveniente mixtura entre aquello que se aprecia con nitidez, y aquello que se expresa. "Manifestar", implica un revelar algo, un mostrar algo. De ahí, por consiguiente, que ambas expresiones no sean ajenas desde un punto de vista lingüístico, pues designan sutilezas que es pertinente destacar.

Por otro lado, el daño ambiental es, en muchos casos, imperceptible, oculto a la vista humana, y que solo se revela a partir de eventos que

${ }^{5}$ Gómez de Silva (2006), p. 452.

${ }^{6}$ Ibid. 
todos reconocemos como anormales o extraños en comparación con los eventos a los cuales los seres humanos se encuentran de cierta manera acostumbrado, como ocurre cuando se espera ver salir el Sol cada mañana. Esa aseveración -ver salir el Sol- además de ser evidente, se manifiesta cada día en la realidad.

Por ello, la imperceptibilidad del daño en cuanto a su manifestación devela una problemática que nuestros tribunales no han sabido determinar de una manera asertiva, con lo cual no sostenemos que los pleitos no se hayan resuelto a favor de los afectados, sino que los informes técnicos solicitados durante la secuela del juicio, como, asimismo, aquellos que los mismos demandados pueden tener $u$ obtener en forma previa de laboratorios extranjeros, son muy costosos, en términos financieros, y de mucha latitud en el tiempo, o en cuanto a su elaboración, lo que provoca en quien tiene que decidir una angustia tanto más grande que su desconocimiento de la materia, prima facie. A esto debemos agregar la falta de preparación de los operadores jurídicos en temáticas técnicas de cierta complejidad, las que requieren de un conocimiento previo que no se adquiere necesariamente con los estudios de pregrado. Las reformas legales, en este sentido, no convierten por arte de magia a aquellos operadores en eruditos o algo por el estilo, de modo que la aserción es correcta desde la perspectiva del foro.

La circunstancia de ventilarse el tema en un procedimiento concentrado regido por normas muy similares a las del juicio sumario, si bien representa un acierto a primera vista, debemos considerar que la estructura del mismo no permite que el juez adquiera la convicción necesaria para zanjar el litigio, dada la complejidad del tema, por una parte, y que sus razonamientos deben propender a buscar la solución más adecuada al problema planteado en un plazo muy breve, por otra. No se trata de restarle importancia al hecho de implementar procedimientos concentrados y breves para enfrentar temáticas como la analizada, sino, más bien, de resaltar la importancia de la formación de los operadores jurídicos. Daniela Peña señala:

"Iniciada una causa, el principal aspecto que dilata su resolución, es la discrepancia entre las partes sobre la concurrencia de las características asociadas a daño ambiental. De esta forma, se constata que aun cuando las demandas logren argumentar la existencia de daño, los cuestionamientos entre las partes sobre la concurrencia de los criterios para definir daño ambiental extienden el tiempo destinado a resolver su existencia, incluso elevándose la causa a la Corte de Apelaciones o Corte Suprema"7.

\footnotetext{
${ }^{7}$ PeÑa (2017), p. 33.
} 
Más aún, para que un experto analice el tema desde la perspectiva técnica, teniendo en contra las alegaciones de los letrados que representan los intereses del demandado, pidiendo que se dicte sentencia por haberse dado los plazos que el código del ramo establece para ello. De hecho, en el caso de las medidas para mejor resolver del art. 159 del Código de Procedimiento Civil, tienen una cota temporal, cuyo vencimiento normalmente es acusado por la parte interesada en que no se evacue el informe pericial. Y si el informe no es concluyente, o, peor aún, no representa un aporte significativo en cuanto norma decisoria litis, el problema se agrava.

\section{DE LA ACCIÓN CIVIL POR DAÑO AMBIENTAL}

Como esta acción tiene por objetivo reparar el daño al ambiente, y la misma es temporal y determinada en cuanto al territorio en razón de quien provoca ese daño, debemos analizar la causalidad del daño y de cómo la conducta del agente contaminador (por llamarlo así), ha sido capaz (apta), técnicamente hablando, de provocar una alteración importante en el entorno (dasain).

La cuestión no es simple, ya que la concurrencia de causas ad infinitum pueden conducir al absurdo, sobre todo en aquellos escenarios en que la contaminación de un lugar se traslade a otro u otros lugares, por acción propia de la naturaleza como sucede con los desechos industriales arrojados al río y que, finalmente, se depositan en el mar o en tierras cultivables.

En la dinámica planteada, una cuestión importante es saber si la contaminación del aire, del suelo o del agua, es considerada un daño ambiental por el legislador. La letra c) del art. $2^{\circ}$ de la Ley n. ${ }^{\circ} 19300$, define contaminación en los siguientes términos:

"la presencia en el ambiente de sustancias, elementos, energía o combinación de ellos, en concentraciones superiores o inferiores, según corresponda, a las establecidas en la legislación vigente",

concepción que no nos parece clara. Esto por cuanto, ¿̇cómo podemos saber a qué se refiere la definición con la expresión "la presencia de elementos en concentraciones superiores o inferiores a las establecidas en la legislación vigente"?

$\mathrm{El}$ art. $2^{\circ}$, letra ll), de la Ley de Bases que define el ambiente como

"el sistema global constituido por elementos naturales y artificiales de naturaleza física, química o biológica, socioculturales y sus interacciones, en permanente modificación por la acción humana 
o natural y que rige y condiciona la existencia y desarrollo de la vida en sus múltiples manifestaciones",

lo hace entendiendo que la misma debe ser complementada con lo señalado en la letra m) del mismo artículo, que conceptualiza lo del "medio ambiente libre de contaminación" como

"aquél en el que los contaminantes se encuentran en concentraciones y períodos inferiores a aquéllos susceptibles de constituir un riesgo a la salud de las personas, a la calidad de vida de la población, a la preservación de la naturaleza o a la conservación del patrimonio ambiental".

Solo apréciese lo que sucede con el art. $19 \mathrm{n} .{ }^{\circ} 8$ de la Carta fundamen$\mathrm{tal}^{8}$, la cual confiere a las personas el derecho a vivir en un ambiente libre de contaminación, discurso que no produce ningún efecto, pues el inciso $2^{\circ}$ del art. 20 no protege el derecho de forma completa mediante la acción constitucional de protección, sino que le impone un requisito de afectación:

"Procederá, también, el recurso de protección en el caso del $\mathrm{N}^{\circ} 8^{\circ}$ del artículo 19, cuando el derecho a vivir en un medio ambiente libre de contaminación sea afectado por un acto u omisión ilegal imputable a una autoridad o persona determinada" 9 .

Por ello, la presencia de elementos, requerida en el art. $2^{\circ}$ letra c), debe entenderse referida a aquellos elementos

"naturales y artificiales de naturaleza física, química o biológica, socioculturales y sus interacciones, en permanente modificación por la acción humana o natural y que rige y condiciona la existencia y desarrollo de la vida en sus múltiples manifestaciones",

a que alude la letra $\mathrm{m}$ ) del mencionado art. $2^{\circ}$ de la ley.

En tal sentido, los requisitos de las letras c), ll) y m), ya citadas, se encuentran satisfechos en cuanto a su sistematización en la Ley de Bases, pues lo que se pretende en la norma ambiental chilena es evitar que se

${ }^{8} \mathrm{El}$ art. 19 n. ${ }^{\circ} 8$ de la Constitución Política de la República, dispone: "El derecho a vivir en un medio ambiente libre de contaminación. Es deber del Estado velar para que este derecho no sea afectado y tutelar la preservación de la naturaleza".

${ }^{9}$ La reforma constitucional de 2005 (Ley n. ${ }^{\circ}$ 20050), modificó la norma citada en un sentido opuesto al analizado, o sea, en relación con el acto u omisión derivado de una potestad pública o de cualquier otra persona. 
produzca un daño al entorno socioambiental de un territorio determinado, cuestión que, si bien posee una adecuación técnico-legislativa, no es, sin embargo, una norma efectiva en su tratamiento ontológico del problema ${ }^{10}$. En efecto, lo que la ley plantea es una especie de "deber ser ambiental" (un locus deóntico), y no se devela el ser de la cuestión (el locus óntico).

Y la cuestión queda clara cuando define la acción como una "reparación" [cuyo objeto es]

"reponer el medio o uno o más de sus componentes a una calidad similar a la que tenían con anterioridad al daño causado [una especie de restitutio in integrum $]^{11}$, o, en caso de no ser ello posible, restablecer sus propiedades básicas" (art. $2^{\circ}$, letra s) de la Ley n. $\left.{ }^{\circ} 19300\right)^{12}$.

\section{MANIFESTACIÓN DEL DAÑO Y PRESCRIPCIÓN.}

Prevención

Debemos, primero, hacer una prevención respecto de la acción que estamos tratando, pues puede pensarse que el requisito de la "manifestación evidente del daño" puede ser considerado desde una doble óptica, esto es, como requisito del daño ambiental o de la acción indemnizatoria, cuestión que nos parece un yerro, desde que el art. 63 de la Ley de Bases y la Ley n. ${ }^{\circ} 20600$ que crea los tribunales ambientales, al referirse al procedimiento, no hacen ninguna distinción. En segundo lugar, no es efectivo que la "manifestación evidente" sea un presupuesto del daño y no de la acción. Si la acción civil tiene por objetivo hacer efectiva la responsabilidad por el daño, la "manifestación evidente del daño ambiental" es uno de los aspectos más importantes a probar. Es decir, no basta con la declaración del daño emanada del tribunal ambiental, sino que en sede civil hay que acreditar los presupuestos básicos de la responsabilidad.

En tercer lugar, debemos prevenir que la Ley n. 20600 que crea los tribunales ambientales, dispone en su art. 46 el procedimiento que se

${ }^{10}$ Debemos hacer la siguiente prevención, pues la expresión 'contaminación' debe observarse desde el locus normativo de las reglas sobre calidad ambiental, lo que restringe en algún sentido el concepto, pero no así la existencia en la realidad de la misma, pues de no existir estas normas administrativas sobre calidad del ambiente, de igual manera se daría el fenómeno de la contaminación.

${ }^{11}$ García (1995), pp. 259-260.

${ }^{12}$ Convengamos que lo primero no es posible debido a que a la naturaleza le tomó millones de años crear el hábitat en el cual sobreviven hoy los seres vivos, aunque por lapsos muy ínfimos en relación con la edad de la Tierra. Lo que sigue allí después de nuestra muerte, es el ambiente. 
debe seguir ante los juzgados civiles que son los competentes en esta materia. De hecho, el procedimiento es concentrado y muy similar al juicio sumario y más aún al actual juicio tributario, de modo que, incluso, con ese cambio, las sentencias que revisaremos no hacen ninguna diferencia en cuanto a los presupuestos tanto normativos como fácticos de la acción indemnizatoria. En otras palabras, no se advierte diferencia sustantiva entre lo señalado en la Ley de Bases y la Ley n. ${ }^{\circ}$ 20600. Dispone al efecto el mencionado art. 46:

"Será competente para conocer de la acción de indemnización de perjuicios por la producción de daño ambiental establecida en la sentencia del Tribunal Ambiental, el juzgado de letras en lo civil con competencia en el lugar donde se produjo el daño".

En consecuencia, no hay necesidad de separar materias en el sentido anotado, desde que será en sede civil donde se deberá acreditar el "hecho" de la manifestación evidente del daño, ya que como se señala en la Ley n. ${ }^{\circ}$ 20600, la causa de pedir en sede civil está dada por la sentencia que declara la existencia del daño. De hecho, en una sentencia reciente del tribunal ambiental (2017), se señalan los requisitos de la acción ambiental: "La controversia del asunto se centra en la acreditación de la legitimación activa y la determinación de la significancia del daño ambiental" ${ }^{13}$, por lo que se excluye probar en esa sede jurisdiccional especial, el hecho de la "manifestación evidente del daño ambiental".

Hechas las prevenciones del caso, arribamos a un tema subyacente de nuestra investigación. Nos referimos a la institución de la prescripción extintiva de la acción indemnizatoria derivada de la contravención al estatuto de responsabilidad previsto en la Ley de Bases sobre el Medio Ambiente, la que dicho sea de paso, es la misma de la acción ambiental.

De esta manera, el art. 63 de la Ley de Bases señala:

"la acción ambiental y las acciones civiles emanadas del daño ambiental prescribirán en el plazo de cinco años, contado desde la manifestación evidente del daño",

lo cual le otorga al tema que tratamos, una enorme importancia. En efecto, si bien el plazo de cinco años otorgado por la Ley de Bases es común a multiplicidad de acciones en el ordenamiento jurídico, la verdad es que tratándose del daño ambiental es un término bastante nimio, sobre todo tomando en cuenta que la mayoría de los trastornos ambientales, cuyas

${ }^{13}$ Sentencia $2^{\circ}$ Tribunal Ambiental, causa rol D-28-2016, de 31 de julio de 2017. 
causas directas provienen de actos del ser humano, tardan cientos de años en manifestarse, parece muy poco serio establecer una cota de cinco años para el ejercicio de la acción.

Sin embargo, creemos que el legislador estimó relevante la temática del plazo, pues para contarlo no se ató a un hecho o a una época determinada, sino a la circunstancia de que el daño se hiciere visible o patente. Es decir, el daño debe exteriorizarse para que recién pueda comenzar a correr el plazo.

Pensamos de cualquier modo que habría sido más apropiado establecer la imprescriptibilidad de la acción. Esto, por las siguientes razones:

a) Porque la naturaleza demora cientos o miles de años en manifestar los cambios que la acción del ser humano haya podido inferir al ambiente como sucede con el calentamiento global, con la destrucción de la capa de ozono por efecto de los gases del tipo invernadero, o el lento y paulatino retiro de los hielos eternos en el sur; situaciones todas que han tardado cientos de años en manifestarse, y que hoy recién se hacen evidentes. En este sentido las medidas que el G8 ha tomado no son eficaces para detener estos procesos, ni, asimismo, lo es la conducta omisiva adoptada por países como USA, China o Chile, cuando se rehúsan a firmar acuerdos en tal sentido.

b) Porque aun cuando el daño al ambiente pueda manifestarse tras un largo proceso, los efectos de esos cambios los sufren también los humanos, incluyendo a aquellos que lo han provocado, de tal manera que el desarrollo de una enfermedad no va a ser evidente ni asociarse a un cambio o trastorno medioambiental, sino al cabo de buena parte de la vida de una persona, como ocurre con la silicosis, enfermedad que se produce por la exposición intensa al sílice -cristal común que se presenta naturalmente en la mayoría de los lechos rocosos y que forma polvo durante el trabajo con minería, la explotación de canteras, la construcción de túneles y al trabajar con muchos minerales metálicos, por lo que las personas que trabajan con vidrio y chorreado de arena, están altamente expuestos a este elemento-, y puede causar esta enfermedad en un año o menos, pero, por lo general, toma al menos diez o quince años de exposición antes de que se presenten los síntomas ${ }^{14}$. Aún así, ¿eso detuvo la producción de arena o la extracción de minerales valiosos?

${ }^{14}$ Para detener esto, el gobierno estadounidense ha tomado algunas acciones, como la OSHA, por la que estableció regulaciones que exigen el uso de equipo protector para limitar la cantidad de polvo de sílice que los trabajadores inhalan. 
En Chile ${ }^{15}$, CODELCO se negó por años a aceptar que el campamento de Chuquicamata cerrara y que todos sus habitantes debían trasladarse a vivir a la ciudad de Calama ${ }^{16}$. Las autoridades de ese entonces basaron su petición de cierre del campamento en las alarmantes cifras de muerte por silicosis que los habitantes del enclave minero registraban en el ámbito nacional. La posición de la empresa (presente en las publicaciones de la época $)^{17}$, se aferraba a la estadística favorable de muertes por esa enfermedad en la ciudad de Calama, alegándose que una mínima cantidad de trabajadores habían muerto por esa causa. No obstante, y ahí está lo interesante del tema, la mayor cantidad de personas que han muerto de silicosis se encuentra concentrada en las regiones del centro-norte del país (es decir, en ciudades como La Serena y Ovalle), que son lugares elegidos por los trabajadores de las divisiones del norte para ir a pasar su vejez o retornar al terruño que los vio nacer. Las dos razones anotadas pueden permitir una relectura de las disposiciones legales que regulan la prescriptibilidad de la acción ambiental.

Por ello, entonces, es relevante que la "manifestación evidente del daño" no se transforme, por desconocimiento técnico de los procesos naturales o de otra índole, en un límite para su ejercicio legítimo por toda persona que se sienta afectada por él, y no solo por autoridades o directamente afectados.

Como bien señala Álvaro Vidal

"cuando la ley alude a las personas que sufrieron el daño o perjuicio, lo hace a quienes por ser víctimas de un daño ambiental están interesados en su reparación"18.

Y quién más interesado que los habitantes de una comunidad que ve instalarse en sus alrededores una compañía minera o una planta de tratamiento de residuos tóxicos o, incluso, de una planta de energía atómica. La determinación específica de las personas que tienen derecho de accionar produce exclusión ${ }^{19}$, porque no todo habitante del país puede accionar. Lo peculiar es que los mismos miembros de la comunidad muy pocas veces van en contra de quienes les dan de comer (las empresas) y, por otro lado,

${ }^{15}$ Bernales, Alcaíno, Solis (2008), pp. 1-6. También en Galleguillos, Concha, Contreras, Abarca, Muñoz, Valenzuela, Villar, Libuy y Crispi (2015), pp. 39-47.

${ }^{16}$ Véase Informe de la Comisión investigadora de la Honorable Cámara de Diputados sobre revisión de la administración de CODELCO (2011).

${ }^{17}$ Véase www.codelco.com/una-batalla-que-codelco-esta-decidida-a-ganar/prontus_ codelco/2011-02-15/190718.html

${ }^{18}$ VIDAL (2008), p. 204.

${ }^{19}$ Ley española ${ }^{\circ}$ 26/2007 de 23 de octubre sobre responsabilidad medioambiental. 
el afuerino es considerado invasor en las comunidades, por lo que sería también muy extraño que alguien quisiera accionar por algo que no ha sufrido en carne propia. El tema es complejo y requiere una mejor lectura.

\section{AnÁlisis de algunas SENTENCIAS}

Las sentencias de los tribunales de justicia marcan una tendencia en orden a establecer criterios básicos de unificación frente a la temática medioambiental. Algunos ejemplos son dignos de imitar, otros, en cambio, asoman como descriterios institucionalizados.

Solo examinaremos algunas sentencias, emanadas de tribunales civiles y de alzada, que son aquellos a los cuales tanto la Ley n.$^{\circ} 19300$ como la n. ${ }^{\circ} 20600$ les han conferido la declaración y posterior conocimiento de las acciones pertinentes.

En primer lugar, una sentencia del $16^{\circ}$ juzgado civil de Santiago, conociendo de una acción ambiental, obligó al demandado a realizar algunas actividades tendientes a reparar el daño causado, las cuales tienen relación con

"limpiar, sacar el material de desecho y recuperar la capa vegetal, en donde se ubican las pertenencias [mineras], y forestar con una plantación de robles de la misma especie en las orillas de los caminos de uso permanente y en las explanadas, socavones y terraplenes en que dicha especie ha sido dañada, y a limpiar y recuperar la capa vegetal en el sector" ${ }^{20}$.

Ahora bien, el tribunal estimó en el considerando 14 de la sentencia: "los elementos ambientales denunciados como dañosos son: la destrucción de dos manantiales y el desvío de cursos de agua [...]", atribuyendo a ciertos hechos la calidad de elementos ambientales, lo cual es una impropiedad, ya que los elementos ambientales son aquellos referidos en las letras c) y 11) del art. $2^{\circ}$ de la ley.

El tribunal confunde lo que es un acontecimiento o evento y la calificación jurídica ambiental del mismo como daño. No indaga en las causas que llevaron a "la destrucción y el desvío de cursos de agua", que resultan ser efectos y no elementos ambientales caracterizados como dañosos por la magistratura.

En sentencia de 29 de diciembre de 2003, la Corte de Apelaciones de La Serena, conoció de varios recursos ${ }^{21}$, los que fueron finalmente

${ }^{20} 16^{\circ}$ Juzgado Civil de Santiago, 6 de mayo de 2002, rol C-65-1999.

${ }^{21}$ Corte de Apelaciones de La Serena, 29 de diciembre de 2003, rol 28.610. 
desechados por aplicación de las reglas de prescripción de la acción ambiental y de la civil concedida en el art. 2332 del Código Civil. Respecto del fondo expuesto en ellos, debemos atender a dos situaciones:

i) la referida a la aplicación de la presunción del art. 426 del Código de Procedimiento Civily

ii) la relativa a la evidencia del daño.

En la primera situación, la Corte aplica la presunción del art. 426 del Código de Procedimiento Civil, norma probatoria muy poco valorada por la judicatura del fondo y que en el caso fue utilizada como fundamento directo de la decisión adoptada de rechazar los recursos.

Señala a este respecto el considerando $6^{\circ}$ de la sentencia, que lo señalado en el informe del perito de la causa (informe agrológico acompañado por la propia demandante a fojas 99), y lo declarado por los testigos referidos, constituyen a juicio de la Corte:

"presunciones graves, precisas y concordantes que acreditan plenamente que el daño ambiental se había producido en forma evidente ya en 1985, época del abandono de las plantaciones, daño que el terremoto ocurrido en 1997, cuando ya la planta estaba cerrada, sólo vino a agravar".

Aunque de manera residual, para nuestro gusto, la Corte toma en consideración las pruebas, instrumental y testimonial, como bases para su presunción, y falla conforme a dicho criterio.

Respecto de lo segundo, la Corte aplica el principio de la "evidencia del daño" en el considerando $7^{\circ}$ de la sentencia, a contrario sensu, o sea, utilizando el argumento tópico como norma decisoria litis. De esta manera, si el daño era evidente para la Corte, lo que hubo de hacer fue sancionar. La utilización del argumento a contrario solo determinó la aplicación de la norma de prescripción de la acción, pero el daño, aquello que sí importaba sancionar, quedó, por tanto, sin condena. Citamos el texto del considerando $7^{\circ}$ :

"Que, sea que el asunto se rija por lo dispuesto en el artículo 2332 del Código Civil, o sea que se rija por lo establecido en el artículo 63 de la Ley 19.300, de todas maneras, a la fecha de notificación de la demanda, habían prescrito la acción ambiental y la acción civil indemnizatoria. En efecto, si, como se ha concluido precedentemente, el daño era evidente ya en 1985, y si el plazo de prescripción se rige por la norma del Código Civil (cuatro años), la acción indemnizatoria prescribió en 1989. Y [si] se rige por la norma de la ley especial publicada en el Diario Oficial de 9 de marzo de 1994, 
atendido lo dispuesto en su artículo $6^{\circ}$ transitorio, dicho plazo (cinco años) concluyó el 8 de junio de 1999" [sic].

La conclusión inevitable del texto es que la Corte buscó los argumentos para denegar la demanda, contribuyendo a que el daño no fuere reparado por el responsable del mismo. La manifestación evidente del daño como principio rector se utiliza en la sentencia además, en forma negativa, lo que determinó, asimismo, la subsistencia del daño producido (y que fue tenido como acreditado por el tribunal de alzada), y sus consecuencias y efectos adversos en el entorno ambiental.

En una sentencia de la Corte Suprema ${ }^{22}$, en relación con la apelación de un fallo de alzada de la Corte de Apelaciones de Valdivia, se estableció que la expresión "malos olores" había sido mal aplicada desde el punto de vista conceptual por el juez del fondo al hacer lugar a la reclamación de la multa que el Servicio de Salud recurrido había cursado a la empresa recurrente, describiendo ese magistrado como "contaminación" algo que no era, al menos en los términos del art. $2^{\circ}$, letra c) de la Ley de Bases del Medio Ambiente.

Y continúa el fallo:

"La citada ley define el término contaminación de la siguiente manera: c) Contaminación: la presencia en el ambiente de sustancias, elementos, energía o combinación de ellos, en concentraciones o concentraciones y permanencia superiores o inferiores, según corresponda, a las establecidas en la legislación vigente, texto que debe ser analizado en concordancia con las letras ll) y m) del mismo artículo $2^{\circ}$ que definen los expresiones 'medio ambiente' y 'medio ambiente libre de contaminación"”

(cuestión a la que aludimos en otro apartado, sobre todo, en aquello referido al concepto de 'elementos' que utiliza la letra c) del mencionado artículo).

Entonces, cuando el considerando $7^{\circ}$ de la sentencia expresa:

"aún cuando esta Corte considerara que los jueces del fondo incurrieron en error de derecho al definir la contaminación de una manera distinta a lo que indican tales disposiciones",

se devela que la Corte no aplicó la norma medioambiental específica de la Ley n. ${ }^{\circ}$ 19300, y que sí aplicó la regla general contenida en el Código

${ }^{22}$ Corte Suprema, 30 de agosto de 2007, rol 3743-2006. 
Sanitario, reconociendo que el juez del fondo había cometido un error al definir el término 'contaminación'.

El tema parece simple, pero no lo es, por dos razones.

Primero, por cuanto al usarse la expresión "malos olores", por el Servicio de Salud, se dio origen a una sanción administrativa, ajena en su calificación a la Ley n. ${ }^{\circ}$ 19300, por lo que parece pertinente advertir que tal calificación, de acuerdo con lo previsto en los arts. 67 y 89, del Código Sanitario, es de naturaleza diversa, por lo que cuando el juez del fondo se da cuenta de ello, trata de adaptar la expresión "malos olores" al tipo administrativo, cometiendo un error de calificación (error de tipo).

Señala el art. 67 mencionado:

"Corresponde al Servicio Nacional de Salud velar porque se eliminen o controlen todos los factores, elementos o agentes del medio ambiente que afecten la salud, la seguridad y el bienestar de los habitantes en conformidad a las disposiciones del presente Código y sus reglamentos".

Por su parte, el art. 89, en su letra a), señala lo siguiente:

"El reglamento comprenderá normas como las que se refieren: a) la conservación y pureza del aire y evitar en él la presencia de materias u olores que constituyan una amenaza para la salud, seguridad o bienestar del hombre o que tengan influencia desfavorable sobre el uso y goce de los bienes".

Convengamos en que ambas normas del Código Sanitario son diversas, siendo la segunda, no obstante, más específica que la primera. No es posible entender a partir de su lectura que los "malos olores" "amenacen la salud, seguridad o bienestar del hombre", pues no existe una afectación significativa de la salud, seguridad o bienestar del hombre, para aplicar una sanción como la señalada, a la empresa.

Y, segundo, por cuanto, si bien el juez del fondo trató de calificar estos malos olores como elementos que afectan el ambiente de la forma en que se señala, la Corte de Apelaciones de Valdivia advirtió de ello en su sentencia, argumento que no fue tomado en cuenta por la Corte Suprema. Es decir, la corte de Valdivia obró bien al negar lugar a la reclamación, ya que la calificación jurídica había sido deficiente de parte del juez del fondo.

Se devela en la sentencia analizada, la existencia de criterios dispares, en especial del juez de primera instancia que calificó algo como "contaminación”, aplicando esa noción en una decisión que produce efectos en la realidad social. 
En otra sentencia de la Corte Suprema ${ }^{23}$, se abordan varios temas jurídicos de interés.

El caso es relevante, porque la Corte Suprema no analiza el tema de la "manifestación evidente del daño" a partir de lo expuesto en el art. 63 de la Ley de Bases, y que el recurrente plantea como vulnerado. En efecto, el considerando $3^{\circ}$ de la sentencia aborda los fundamentos tendientes al desconocimiento de la ley ambiental (y que se exponen luego en su considerando $9^{\circ}$ ), señalando: "el recurrente manifiesta que se ha desobedecido lo preceptuado en los artículos 3, 51, 53 y 63 de la Ley No 19.300”.

Esa "desobediencia" emana de que en el aludido considerando, la recurrente señala:

"la exigencia de que el interesado no conozca el daño antes del ejercicio de la demanda respectiva transformaría a las citadas normas en inoperantes, pues la ley entiende que esta clase de daño es de difícil determinación y por ello ha dispuesto que el plazo de prescripción ha de contarse desde su manifestación evidente, con lo que se violentaría el artículo 63 de la Ley N 19300” [sic],

para luego, sostener:

"los artículos en comento fueron infringidos al agregarles un requisito de interposición que no contemplan, el que, por lo demás, no existe siquiera en el sistema ordinario de responsabilidad civil”;

esto es, el conocimiento del daño en forma previa al ejercicio de las acciones.

El problema, entonces, se reduce a establecer dos cosas:

a) si existe algún antecedente cierto del cual se pueda inferir el daño y

b) si se puede entender vulnerado el art. 63 desde que la sentencia no aborda el tema desde la perspectiva de la manifestación evidente del daño.

En cuanto a la letra a), es del todo razonable que el contrato existente entre algunas de las partes involucradas en el pleito le haya asignado fecha cierta al evento, entendiendo que existe un antecedente que sirve de base al pronunciamiento judicial. O sea, cuando la Corte le resta importancia al argumento de la manifestación evidente del daño, está señalando que es irrelevante que el daño exista y cause todos sus efectos, pues si la empresa contaminante no tomó parte en el contrato, no le es oponible la ocurrencia del daño. Y ahí está el problema, pues la Corte no reconoce

${ }^{23}$ Corte Suprema, 24 de enero de 2008, rol 3807-2006. 
al contrato como un punto de apoyo para determinar la "manifestación evidente del daño" provocado.

Respecto de la interrogante de la letra b), y de acuerdo con lo argumentado con antelación, es razonable concluir que no se ha vulnerado el art. 63 desde que resulta necesario cumplir con la exigencia de conocimiento, pues desde ese saber real se puede inferir -en el sentido de colegir- que ha existido un daño, y que este debe ser indemnizado.

Luego de la dictación en 2012 de la Ley n. ${ }^{\circ}$ 20600, no se aprecia un cambio en criterios que hagan presumir una especie de modificación del estatuto de responsabilidad legal ambiental ni menos cambios más que adjetivos en la tramitación y duración de los procesos, por lo que debemos entender que los tribunales con competencia en lo civil, han continuado su labor, teniendo como base de su competencia, el fallo de un tribunal ambiental.

En la sentencia del $2^{\circ}$ tribunal ambiental de 31 de julio de 2017, se señala lo siguiente:

"existen dos elementos necesarios para encontrarse en presencia de un daño ambiental. En primer lugar, debe tratarse de un deterioro o menoscabo inferido al medio ambiente, lo que en el presente caso se manifiesta como consecuencia de las afectaciones a los componentes agua, suelo, fauna, ecosistema y biodiversidad. En segundo lugar, se requiere que se trate de un 'perjuicio o menoscabo' significativo, lo que en la especie se configuraría, por cuanto se trata de un daño de suma gravedad, ya que con las obras ejecutadas se habría afectado, y se continuaría afectando, el ecosistema conformado por el lago, su valor paisajístico, la biodiversidad que sustentaba, y toda su cuenca hidrográfica. Concluye que el lugar intervenido presentaría un deterioro ambiental y sustenta sus afirmaciones en el informe elaborado por el Centro de Ecología Aplicada" ${ }^{24}$.

Podemos inferir dos cuestiones relevantes de los argumentos sostenidos por la reclamante:

a) que él entiende que hubo daño ambiental y que este manifestó en la afectación de componentes del agua, del suelo, etc. y

b) que existió un perjuicio o menoscabo significativo, lo cual implica aumentar la carga de la prueba con una expresión ambigua y fuera de todo contexto de responsabilidad.

Que algo sea significativo no es que sea de summa gravedad, no hace que la reparación crezca en entidad y en cantidad. Una sentencia de casación de la Corte Suprema cita la siguiente doctrina:

${ }^{24}$ Sentencia $2^{\circ}$ Tribunal Ambiental, causa rol D-28-2016, de 31 de julio de 2017, p. 9. 
"la ley no contiene parámetros que permitan una calibración objetiva de la significación de los daños infligidos al medio ambiente, esta determinación queda entregada en definitiva a lo que resuelvan al respecto los jueces del fondo" 25 ,

de lo que debemos colegir que ausente la determinación objetiva del daño como significativo, tanto el autor citado como el tribunal caen en la trampa de la determinación subjetiva de la significación del daño, pasando la manifestación del mismo a un aparente segundo plano, cuando utilizan el adverbio mencionado. El tribunal entiende en tal sentido que el daño es significativo cuando "afecta los distintos componentes del medio ambiente, esto es, suelo, vegetación y escorrentías superficiales".

Ahora, respecto de la manifestación evidente del daño, en la sentencia el tribunal señala lo siguiente en su considerando $17^{\circ}$ :

"Que en el último acápite se denuncia la conculcación de lo dispuesto en el artículo 63 de la Ley $\mathrm{N}^{\circ} 19.300$, puesto que tanto la acción ambiental como las acciones civiles emanadas del daño ambiental prescriben en el plazo de cinco años, contado desde su manifestación evidente. Explica que de los dichos de los demandantes fluye que tienen conocimiento del funcionamiento del vertedero hace casi veinte años, el que se encuentra operativo desde el año 1996. Así, el daño se hace patente, según los actores desde aquella data, cuestión que deja de manifiesto la extemporaneidad de la acción. Añade que no se puede establecer que el daño se evidencia en la fecha de interposición del recurso de protección, en el año 2014, pues no es efectivo, máxime si se acusa que provoca muerte de animales, acreditándose la muerte de uno en el año 2006. En este contexto refiere que se trajo a la vista los autos rol 282-2012, en que el actor al relatar los hechos que motivan la demanda, expresamente refiere que hace diez años no ha podido trabajar y hace doce o catorce se originó el daño al establecerse el vertedero en el predio colindante";

de modo que en el caso concreto del vertedero, suponen los reclamantes que la manifestación evidente se ha dado desde su construcción y entrada en operaciones.

Sin embargo, aquello no es necesariamente así, ya que la simple existencia de un vertedero, donde se supone que se tratan los residuos domiciliarios aplicando la tecnología pertinente, no permite sostener que existe una afectación del suelo o del agua pertenecientes al ecosistema.

${ }^{25}$ Sentencia de Casación CS, rol D-13-2015. También Valenzuela (2010) p. 318. 
Se requiere que el daño, esto es, el hecho o hechos dañosos sean consecuencia del manejo desprolijo de tales residuos. Debe haber evidencia de la ocurrencia de aquello y de su íntima relación causal, aspectos ambos que permitan al juez adquirir el grado de convicción mínimo de que en el caso sometido a su conocimiento, fue una actividad humana o su omisión la que permitió que los efectos dañosos se produjeran.

\section{CONCLusiones}

Existe una disfunción entre los conceptos que la Ley de Bases del Medio Ambiente ha definido de manera expresa, y la forma en que nuestros tribunales han entendido que los mismos deben aplicarse en casos concretos.

No resulta atendible que en algunos casos, la judicatura entienda una cosa y la aplique una forma deficiente, sobre todo pensando que tal aplicación produce efectos erga omnes, aun cuando la ley así no lo disponga expresamente.

La "manifestación del daño" es, sin duda alguna, el punto de partida que se requiere para incoar eficazmente la acción civil derivada del daño ambiental. Pero esperar que aquella manifestación, que muchas veces depende de la naturaleza de las cosas, se haga evidente dentro de un plazo establecido por los seres humanos, se presenta como una muestra de arrogancia que solo es factible en la medida que el legislador enmiende su camino, estableciendo la imprescriptibilidad de la acción.

Tal vez los efectos indemnizatorios no alcancen a los perjudicados, pero es ostensible que lo puedan hacer respecto de los herederos, o del Estado, ya que es este el depositario final de dichos efectos.

Debiera en tal sentido tener la acción ese componente público (acción popular) que evite de alguna forma la impunidad de las empresas o sujetos activos del daño ambiental.

La existencia de normativa procesal ambiental por la Ley n. ${ }^{0}$ 20600, no ha sido óbice para que los tribunales civiles que conocen de la acción indemnizatoria por daño ambiental alteren de forma sustantiva la forma en que la responsabilidad extracontractual debe ser acreditada en juicio, ello debido a que, si bien el procedimiento se ha modificado, no así la manera de aplicar los principios sustantivos existentes en la legislación común civil. En otras simples palabras, tanto el juez que conoce de la acción como las normas legales aplicables al caso (estatuto de responsabilidad extracontractual) son las mismas.

Lo único que permitió la creación de los tribunales ambientales, es que jueces especializados establezcan de manera indubitada la existencia del daño ambiental, sin perjuicio de estimar que al reclamante se le va un 
tiempo precioso en litigar en dos instantes que perfectamente pudieron ser parte de un mismo sistema procedimental. No podemos olvidar que la labor judicativa es el último eslabón de un sistema democrático, por lo que la ineficacia en el acceso a la justicia, unido a la extensión indebida de los procesos, producen un sesgo de inseguridad en las personas que el Estado debe propender a mantener en rangos aceptables, imperativo que no se cumple en el instante mismo de establecer tribunales diversos para conocer de un mismo asunto, o de un asunto con raíces comunes.

Por último, afirmamos nuestra convicción de que la "manifestación evidente del daño ambiental" es un requisito de la acción civil indemnizatoria, que en la medida de lo expresado en el art. 63 de la Ley n. ${ }^{\circ}$ 19300, es también aplicable a las acciones especiales ambientales de que trata la Ley n. ${ }^{\circ}$ 20600. Esta doble circunstancia, por tanto, no representa un conflicto relevante a la hora de juzgar la procedencia de una u otras, de huelga que, sometido el asunto al conocimiento del tribunal con competencia en lo civil, uno de los presupuestos fácticos a probar será, sin duda, el de la manifestación evidente anotada.

\section{BibliogRAFÍA}

Bernales, Bélgica, Juan Alcaíno, Rodrigo Solis (2008). "Situación de exposición laboral a sílice en Chile". Revista Ciencia y Trabajo. n. ${ }^{\circ}$ 10. Santiago.

Bermúdez Soto, Jorge (2007). Fundamentos del derecho ambiental .Valparaíso: Ediciones Universitarias de Valparaíso.

Corral Talciani, Hernán (2004). Lecciones de responsabilidad extracontractual. Santiago: Editorial Jurídica de Chile.

De Mora, José Joaquín (2007). Diccionario manual de sinónimos y antónimos de la lengua española. Madrid: Editorial VOX.

Gallegulllos B, Sylvia, Marisol Concha B., Gustavo Contreras T., Gretchy Abarca C., Albert O. Muñoz V., Esteban Valenzuela S., Pablo Villar M., Matías Libuy R. y Francisca CRISPI G. (2015). "La silicosis: cun problema de salud pública prioritario para Chile?". Revista Chilena de Enfermedades Respiratorias. Vol. 31, n. ${ }^{\circ}$ 1. Santiago.

García Garrido, Manuel J. (1995). Derecho Privado Romano. $6^{\mathrm{a}}$ ed. Madrid: Editorial Dykinson.

Gómez de Silva, Guido (2006). Breve diccionario etimológico de la lengua española. México: Fondo Cultura Económica.

Heidegger, Martin (1997). Ser y tiempo. (trad.) Jorge Eduardo Rivera. Santiago: Editorial Universitaria.

Muñoz Pérez, Enrique (2015). "Trascendencia, mundo y libertad en el entorno de Ser y Tiempo de Martin Heidegger”. Revista Veritas. n. ${ }^{\circ} 32$. Santiago. 
Peña Barrientos, Daniela (2017). Responsabilidad por daño ambiental en chile: ¿existe una real protección del medio ambiente? Análisis de las sentencias que ordenaron reparar daño ambientaly su posterior cumplimiento. Tesina. Santiago: Universidad de Chile.

Valenzuela Fuenzalida, Rafael (2010). El derecho ambiental: presente y futuro. Santiago, Editorial Jurídica de Chile.

Vidal Olivares, Álvaro (2008). "Las acciones emanadas del daño ambiental y el régimen de responsabilidad aplicable", en Cuadernos de Análisis Jurídico. Santiago: Editorial Universidad Diego Portales. Vol. 4.

Vidal Olivares, Álvaro (2007). "Las acciones civiles derivadas del daño ambiental en la ley 19.300". Revista de Derecho de la Pontificia Universidad Católica de Valparaíso. Vol. Xxix. Valparaíso.

Wittgenstein, Ludwig (2004). Investigaciones filosóficas. (trad.) Alfonso García Suárez y Ulises Moulines. Barcelona: Editorial Crítica.

\section{Normas jurídicas}

Ley n. ${ }^{\circ}$ 19300, 1994 (Chile).

Ley n. ${ }^{\circ}$ 20600, 2012 (Chile).

Ley n. ${ }^{\circ}$ 26/2007 sobre responsabilidad medioambiental de 23 de octubre (España).

$$
\text { Jurisprudencia }
$$

Sentencia de la Corte de Apelaciones de La Serena, 29 de diciembre de 2003, rol 28.610.

Sentencia de la Corte Suprema, 30 de agosto de 2007, rol 3743-2006.

Sentencia de la Corte Suprema, 24 de enero de 2008, rol 3807-2006.

Sentencia de la Corte Suprema, 7 de marzo de 2017, rol D-13-2015.

Sentencia del $16^{\circ}$ Juzgado Civil de Santiago, 6 de mayo de 2002, rol C-65-1999.

Sentencia del $2^{\circ}$ Tribunal Ambiental, 31 de julio de 2017, rol D-28-2016.

Sentencia del $2^{\circ}$ Tribunal Ambiental, 23 de noviembre de 2018, rol D-26-2016.

Sentencia del $2^{\circ}$ Tribunal Ambiental, 22 de noviembre de 2018, rol D-27-2016.

Sentencia del $3^{\circ}$ Tribunal Ambiental, 31 de julio de 2017, rol D-28-2016.

\section{Otros recursos}

Informe de la Comisión Investigadora de la H. Cámara de Diputados sobre revisión de la administración de CODELCO (2011), disponible en www.camara. $\mathrm{cl} /$ pdf.aspx?prmid=3554\&prmtipo=SOBRETABLA [fecha de consulta: 28 de mayo de 2019].

Columna EMOL: www.codelco.com/una-batalla-que-codelco-esta-decidida-aganar/prontus_codelco/2011-02-15/190718.html [fecha de consulta: 15 de febrero de 2015]. 